\title{
Double-Win Properties Response of Mechanical and Hydrogen Absorption in Melt-Spun Ti-Zr-Ni-Cr Amorphous Metals
}

\author{
Shuiming Huang ${ }^{1} \cdot$ Huihui Song ${ }^{1} \cdot$ Yuhu Hu$^{1} \cdot \mathrm{Kai} \mathrm{Xu}^{1} \cdot \mathrm{Chao} \mathrm{Zhou}^{2} \cdot \mathrm{Xueling} \mathrm{Hou}^{1} \mathbb{C}$
}

Received: 9 September 2021 / Accepted: 1 December 2021 / Published online: 20 January 2022

(c) The Author(s) 2022

\begin{abstract}
The effect of spinning rates on mechanical properties and hydrogen absorption/desorption properties of $\mathrm{Ti}_{47} \mathrm{Zr}_{31} \mathrm{Ni}_{14} \mathrm{Cr}_{8}$ amorphous ribbons have been investigated in the present work. A fully amorphous structure was confirmed by $\mathrm{x}$-ray diffraction (XRD) and transmission electron microscopy (TEM) analysis of the ribbons obtained from spinning rates of $30 \mathrm{~m} \mathrm{~s}^{-1}$ to $45 \mathrm{~m} \mathrm{~s}^{-1}$. The uniformity of amorphous ribbons and their mechanical properties were improved with the increase in the spinning rate. Scanning electron microscopy (SEM) revealed that the fracture surface of amorphous ribbons had a cleavage feature and vein-like pattern when the spinning rates were $30 \mathrm{~m} \mathrm{~s}^{-1}$ and $45 \mathrm{~m} \mathrm{~s}^{-1}$, respectively. Because of the influence of flow units on the kinetic process of hydrogen absorption, the hydrogenation kinetics and hydrogen desorption capacity of amorphous ribbons were enhanced with the increased spinning rates. After the amorphous ribbons absorbed a large amount of hydrogen, $\mathrm{ZrH}_{2}, \mathrm{TiH}_{2}$, and $(\mathrm{ZrTi})_{2} \mathrm{Ni}_{7}$ crystalline phases were formed from the amorphous matrix. Hydrogen promotes amorphous phase decomposition and the crystallinity of the new phases led to deterioration of the mechanical properties.
\end{abstract}

Keywords Amorphous ribbons $\cdot$ mechanical properties $\cdot$ hydrogen absorption properties $\cdot$ spinning rate

\section{Introduction}

Amorphous alloys have attracted much attention due to their excellent corrosion resistance and hydrogen absorption properties, especially mechanical properties such as outstanding mechanical strength, greater elasticity than crystalline alloys, high hardness, and good fatigue resistance. ${ }^{1-5}$ Amorphous alloys refer to alloys in which atoms are arranged in a topological disorder in three-dimensional space and are relatively stable in a certain temperature range. ${ }^{6,7}$

There are no defects such as vacancies, grain boundaries, and stacking faults in amorphous alloys; this special structure gives amorphous alloys different mechanical properties and fracture mechanisms as compared to crystal alloys. The research on the mechanical properties of amorphous alloys is mainly a study of the mechanical properties of bulk

Xueling Hou

flybird1656@163.com

1 School of Materials Science and Engineering, Shanghai University, Shanghai 200072, China

2 Science and Technology on Vacuum Technology and Physics Laboratory, Lanzhou Institute of Physics, Lanzhou 730000, China amorphous and amorphous composite ribbons. ${ }^{8-10}$ There are few studies on melt-spun amorphous ribbons obtained by melt-spinning method because of their brittleness and fracture toughness. Therefore, some studies have been done to improve the ductility and toughness of amorphous ribbons, including changing the chemical composition of alloy, the melt-spinning rate, and heat-treatment process. ${ }^{11-13}$

Due to the long-range disorder structure of amorphous alloys, there are areas where the atomic arrangement is loose or the interatomic bond is weak, which provides a channel for the diffusion and occupancy of hydrogen; these mechanisms have led to extensive research. ${ }^{14-18}$ Ti-based and Zr-based amorphous alloys have a strong affinity for $\mathrm{H}$ atoms, and they have been extensively studied. ${ }^{19-22}$ The hydrogen absorption characteristics of amorphous alloys are as follows: First, hydrogen preferentially occupies a lowerenergy level in amorphous alloys and forms an amorphous solid/solution phase. Second, relative to crystalline alloys, amorphous alloys have a low activation temperature and hydrogen absorption temperature. Therefore, amorphous ribbons have broad application prospects in the purification of hydrogen, hydrogen storage alloys, and hydrogen permeation membranes. ${ }^{23-25}$ 
In the present work, the effects of the spinning rate on the phase structure and mechanical properties were investigated, as well as the effects on the hydrogen absorption/ desorption properties. The results revealed the relationship between mechanical properties and fracture mechanism at room temperature, and also explain the evolution of phase in hydrogen absorption.

\section{Materials and Methods}

Ingots with stoichiometric composition $\mathrm{Ti}_{47} \mathrm{Zr}_{31} \mathrm{Ni}_{14} \mathrm{Cr}_{8}$ were prepared by arc melting the mixture of pure metals $\mathrm{Ti}$ (99.99\%), Zr (99.99\%), Ni (99.99\%), and Cr (99.99\%) in an argon atmosphere. The ingots were re-melted four times for homogenization. Ribbons were obtained by melt spinning on a copper roller in an argon atmosphere, and the meltspinning rates were $15 \mathrm{~m} \mathrm{~s}^{-1}, 30 \mathrm{~m} \mathrm{~s}^{-1}, 35 \mathrm{~m} \mathrm{~s}^{-1}, 40 \mathrm{~m} \mathrm{~s}^{-1}$, and $45 \mathrm{~m} \mathrm{~s}^{-1}$. During the melt-spinning process, the distance between the orifice of a quartz crucible and a copper wheel surface was maintained at $7.5 \mathrm{~mm}$. The chamber pressure was maintained at $0.05 \mathrm{MPa}$.

The phase structure was characterized by a D/Max-2200 $\mathrm{x}$-ray diffractometer (Rigaku Corporation, Akishima-Shi, Tokyo, Japan) using $\mathrm{Cu} \mathrm{K} \alpha$ radiation. The thermal behaviors were analyzed by differential scanning calorimetry (DSC, PE DIAMOND) at a heating rate of $20 \mathrm{~K} \mathrm{~min}^{-1}$ under an argon atmosphere. The microstructure and chemical composition were investigated using a JSM-6700F scanning electron microscope with an energy-dispersive spectrometer, and a JEM-2010F transmission electron microscope equipped with energy dispersive $\mathrm{x}$-ray spectroscopy (EDX) functionality. The samples were prepared with a circle of $2 \mathrm{~mm}$ in diameter and then thinned using a double-jet electrolytic thinning device (MTP-1A) with 20\% perchloric acid and $80 \%$ acetic acid. The mechanical properties, such as tensile strength $\left(\sigma_{\mathrm{b}}\right)$, elongation $(\delta)$, and elastic modulus $(E)$, were measured with a Zwick electronic universal testing machine operating at a loading rate of $8.3 \times 10^{-6} \mathrm{~m} \mathrm{~s}^{-1}$ at room temperature. The hydrogen absorption/desorption properties were carried out in a fully automated hydrogen storage setup (fully automatic PCI monitor produced by Suzuki Shokan Co., Ltd.) at room temperature under hydrogen pressure of 3 $\mathrm{MPa}$. The activation procedure involved heating the sample in vacuum for $2 \mathrm{~h}$ at $473 \mathrm{~K}$.

\section{Results and Discussion}

Figure 1a presents the evolution of the $\mathrm{x}$-ray diffraction (XRD) patterns of $\mathrm{Ti}_{47} \mathrm{Zr}_{31} \mathrm{Ni}_{14} \mathrm{Cr}_{8}$ alloy ribbons with spinning rates increasing from $15 \mathrm{~m} \mathrm{~s}^{-1}$ to $45 \mathrm{~m} \mathrm{~s}^{-1}$. The XRD patterns show different phase structures with different spinning rates. When the spinning rate was $15 \mathrm{~m} \mathrm{~s}^{-1}$, the XRD patterns in the $\mathrm{Ti}_{47} \mathrm{Zr}_{31} \mathrm{Ni}_{14} \mathrm{Cr}_{8}$ alloy confirmed mainly the presence of $\alpha$-Ti (PDF\# 65-3362), $\alpha-Z r$ (PDF\# 89-4892), and $\mathrm{Ti}_{2} \mathrm{Ni}$ (PDF\# 18-0898). However, with the spinning rate ranging from $30 \mathrm{~m} \mathrm{~s}^{-1}$ to $45 \mathrm{~m} \mathrm{~s}^{-1}$, the XRD patterns of ribbons exhibited only a broad diffraction peak. These results indicated that the $\mathrm{Ti}_{47} \mathrm{Zr}_{31} \mathrm{Ni}_{14} \mathrm{Cr}_{8}$ alloy ribbons presented a disordered structure in terms of atomic arrangement and consisted of a single amorphous phase when melt-spun at high speed. It was also revealed that the phase structure changed from crystalline to amorphous when the spinning rate increased from $15 \mathrm{~m} \mathrm{~s}^{-1}$ to $45 \mathrm{~m} \mathrm{~s}^{-1}$.

For DSC analysis of the amorphous ribbons, we selected representative melt-spun samples when the spinning rate was $30 \mathrm{~m} \mathrm{~s}^{-1}$ and $45 \mathrm{~m} \mathrm{~s}^{-1}$. The results of DSC curves are shown in Fig. 1b. The measurement results indicate that the DSC curves had an exothermic peak. It can be seen from the DSC curve that when the spinning rate was $30 \mathrm{~m} \mathrm{~s}^{-1}$ and $45 \mathrm{~m} \mathrm{~s}^{-1}$, the glass transition temperature was $785 \mathrm{~K}$ and $820 \mathrm{~K}$, respectively. It was also indicated that when the spinning rate reached $30 \mathrm{~m} \mathrm{~s}^{-1}$, the ribbons contained an amorphous phase. Thus, the glass transition temperature and glass transition behavior were related to the spinning rate. It was indicated that as the spinning rate increased, the thermal stability of the amorphous ribbon was strengthened. This is also consistent with published results on $\mathrm{Ti}-\mathrm{Zr}-\mathrm{Ni}-\mathrm{Cr}-\mathrm{V}$ amorphous ribbons. ${ }^{13}$
Fig. 1 (a) XRD and (b) DSC curves of $\mathrm{Ti}_{47} \mathrm{Zr}_{31} \mathrm{Ni}_{14} \mathrm{Cr}_{8}$ alloys ribbons produced by melt spinning at different spinning rates.
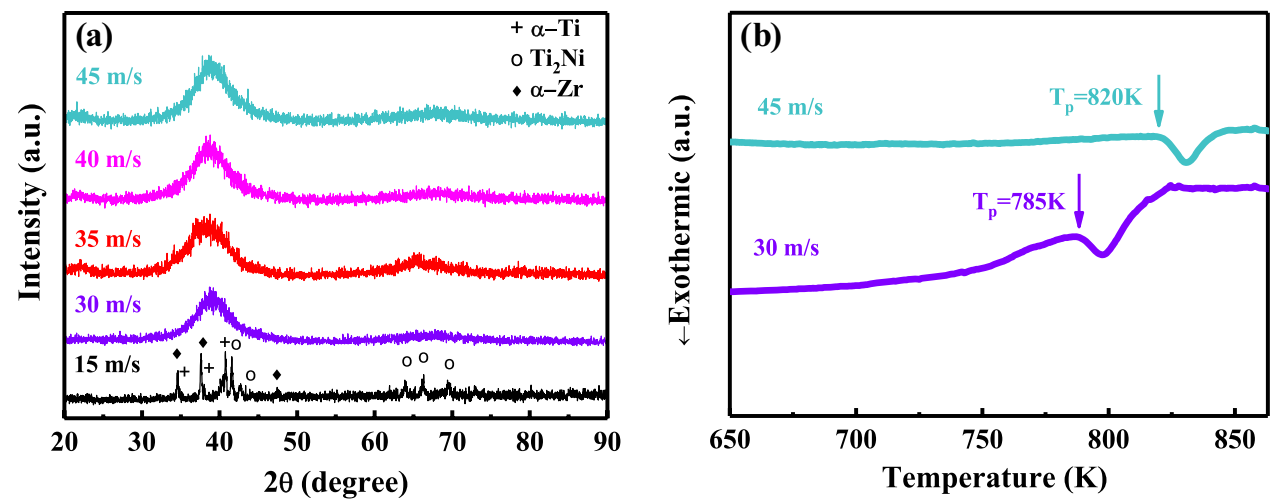
Figure 2 shows typical TEM and high-resolution transmission electron microscopy (HRTEM) images of the $\mathrm{Ti}_{47} \mathrm{Zr}_{31} \mathrm{Ni}_{14} \mathrm{Cr}_{8}$ alloy with spinning rates of $30 \mathrm{~m} \mathrm{~s}^{-1}$ and $45 \mathrm{~m} \mathrm{~s}^{-1}$. Figure $2 \mathrm{a}$ reveals that the surface is uneven and has gray and black areas in the amorphous matrix. The HRTEM image shows a disordered structure with about 80 -nm black nano-regions in the amorphous matrix. The EDX analysis confirmed that there were differences in chemical composition in the I, II, and III regions. It was observed that the concentration profile of different elements showed diverse trends. At the black nano-region, the Ni content was highest and the $\mathrm{Ti}$ and $\mathrm{Zr}$ content was lower than in other areas when the spinning rate was $30 \mathrm{~m} \mathrm{~s}^{-1}$. This means that there was a segregation of $\mathrm{Ni}$ in this region, while $\mathrm{Ti}$ and $\mathrm{Zr}$ were diluted during the melt-spinning process of $\mathrm{Ti}_{47} \mathrm{Zr}_{31} \mathrm{Ni}_{14} \mathrm{Cr}_{8}$ alloy. Combined with Fig. 2a, c and Table I, the composition of the amorphous alloy was inhomogeneous when the spinning rate was $30 \mathrm{~m} \mathrm{~s}^{-1}$.

As shown in Fig. $2 b$, when the spinning rate reached 45 $\mathrm{m} \mathrm{s}^{-1}$, the surface was even and flat. The corresponding selected-area diffraction patterns for region $\mathrm{B}$ are displayed in the inset of Fig. 2b, which shows only the amorphous ring, confirming the presence of an amorphous structure. Figure $2 \mathrm{~d}$ shows that the surface of the melt-spun ribbons was flat. And the disordered atomic arrangement indicated that the matrix was a homogeneous amorphous structure. The EDX analysis confirmed that the chemical composition in the IV region was the same as the nominal composition when the spinning rate was $45 \mathrm{~m} \mathrm{~s}^{-1}$. Compared with the spinning rate of $30 \mathrm{~m} \mathrm{~s}^{-1}$, EDX confirmed that the chemical composition was more uniform and that the amorphous structures of melt-spun ribbons were more homogeneous and showed a fully disordered structure when the spinning rate reached $45 \mathrm{~m} \mathrm{~s}^{-1}$. Therefore, the melt-spun ribbons had a more homogeneous amorphous structure with an increase

Table I The chemical composition of $\mathrm{Ti}_{47} \mathrm{Zr}_{31} \mathrm{Ni}_{14} \mathrm{Cr}_{8}$ alloy in atomic percentage

\begin{tabular}{llllc}
\hline Region & $\mathrm{Ti}($ at.\%) & $\mathrm{Zr}($ at.\%) & $\mathrm{Ni}$ (at.\%) & $\mathrm{Cr}$ (at.\%) \\
\hline I & $42.6 \pm 0.03$ & $23.7 \pm 0.03$ & $21.5 \pm 0.03$ & $12.2 \pm 0.03$ \\
II & $42.0 \pm 0.03$ & $22.4 \pm 0.03$ & $26.8 \pm 0.03$ & $8.8 \pm 0.03$ \\
III & $47.0 \pm 0.03$ & $31.6 \pm 0.03$ & $13.7 \pm 0.03$ & $7.7 \pm 0.03$ \\
IV & $46.8 \pm 0.03$ & $31.2 \pm 0.03$ & $13.9 \pm 0.03$ & $8.1 \pm 0.03$ \\
\hline
\end{tabular}

Fig. 2 TEM micrographs of melt-spun ribbons of the $\mathrm{Ti}_{47} \mathrm{Zr}_{31} \mathrm{Ni}_{14} \mathrm{Cr}_{8}$ alloy: (a) meltspun $\left(30 \mathrm{~m} \mathrm{~s}^{-1}\right) \mathrm{Ti}_{47} \mathrm{Zr}_{31} \mathrm{Ni}_{14} \mathrm{Cr}_{8}$ alloy; (b) melt-spun ( $45 \mathrm{~m} \mathrm{~s}^{-1}$ ) $\mathrm{Ti}_{47} \mathrm{Zr}_{31} \mathrm{Ni}_{14} \mathrm{Cr}_{8}$ alloy; corresponding selected-area diffraction patterns for region $B$ are shown in the inset. HRTEM micrographs taken from $\mathrm{Ti}_{47} \mathrm{Zr}_{31} \mathrm{Ni}_{14} \mathrm{Cr}_{8}$ alloy compacted in vacuum; (c) meltspun $\left(30 \mathrm{~m} \mathrm{~s}^{-1}\right) \mathrm{Ti}_{47} \mathrm{Zr}_{31} \mathrm{Ni}_{14} \mathrm{Cr}_{8}$ alloy; (d) melt-spun ( $\left.45 \mathrm{~m} \mathrm{~s}^{-1}\right)$ $\mathrm{Ti}_{47} \mathrm{Zr}_{31} \mathrm{Ni}_{14} \mathrm{Cr}_{8}$ alloy.
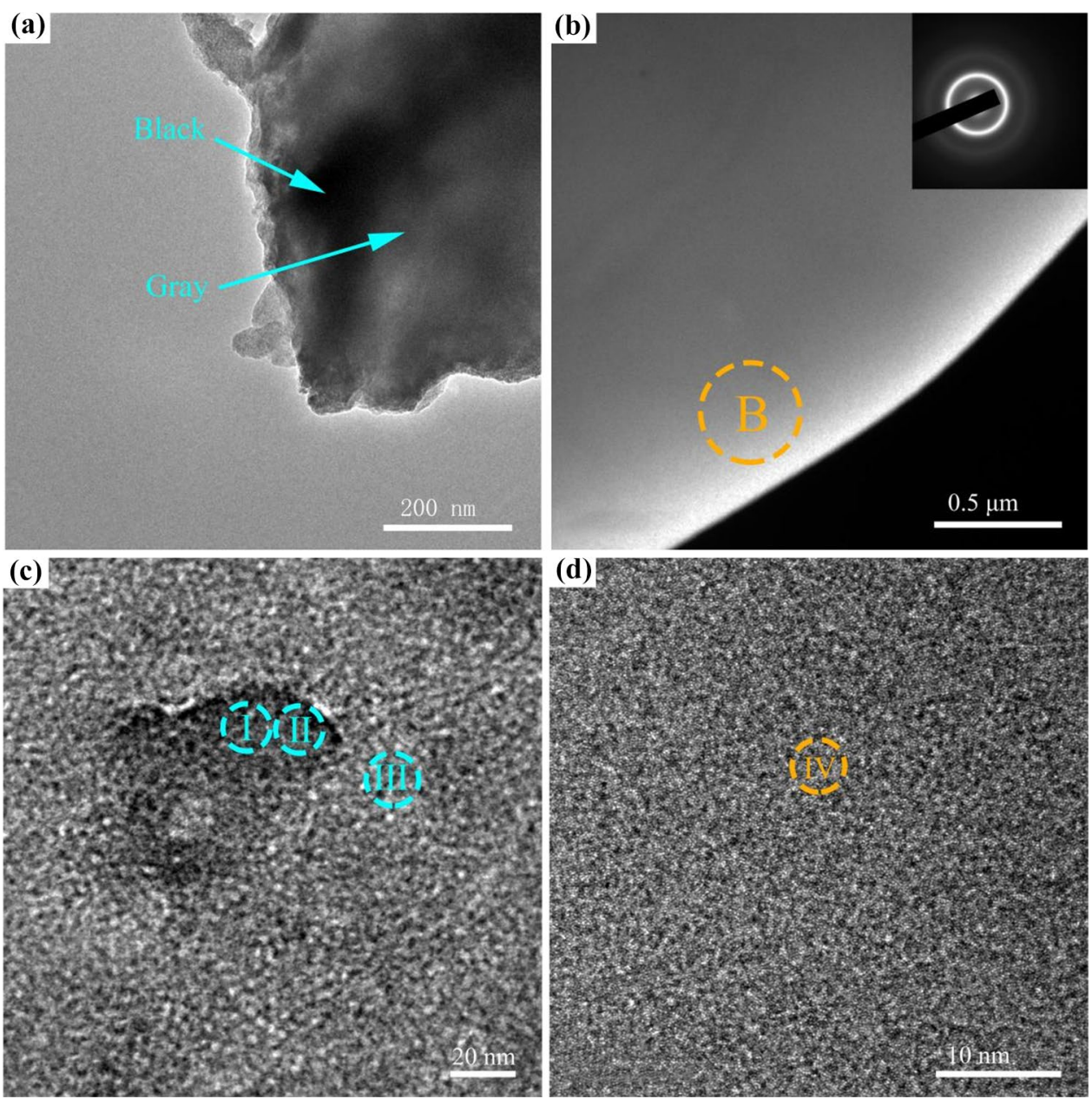
in the spinning rate. This consistency with the XRD and DSC results provides further confirmation that the melt-spun ribbons were amorphous when the spinning rate reached 45 $\mathrm{m} \mathrm{s}^{-1}$.

Figure 3a shows the Zwick electronic universal testing machine and the schematic diagram of the location during stretching. Figure $3 \mathrm{~b}$ displays a dimension diagram of a tensile melt-spun ribbon with length of $55 \mathrm{~mm}$, width of $4 \mathrm{~mm}$, and thickness of $0.3 \mathrm{~mm}$ when the spinning rate was 30 $\mathrm{m} \mathrm{s}^{-1}$. Figure $3 \mathrm{c}$ presents the tensile stress-strain curves of amorphous ribbons under different spinning rates from 30 $\mathrm{m} \mathrm{s}^{-1}$ to $45 \mathrm{~m} \mathrm{~s}^{-1}$. Table II shows that the tensile strength of amorphous ribbons increased significantly from $224 \mathrm{MPa}$ at a spinning rate of $30 \mathrm{~m} \mathrm{~s}^{-1}$ to $542 \mathrm{MPa}$ at a spinning rate of $45 \mathrm{~m} \mathrm{~s}^{-1}$. When the spinning rate was increased from 30 $\mathrm{m} \mathrm{s}^{-1}$ to $45 \mathrm{~m} \mathrm{~s}^{-1}$, the elongation exhibited a small increasing tendency from $0.28 \%$ to $1.1 \%$, and the elastic modulus decreased from 97.3 GPa to 44.6 GPa. Compared with other ribbons, the stress-strain curve revealed an interesting phenomenon: a series of stress drop phenomena began to appear over time when the spinning rate reached $45 \mathrm{~m} \mathrm{~s}^{-1}$. This is a serrated flow behavior, which means a good toughness compared with ribbons of other spinning rates.
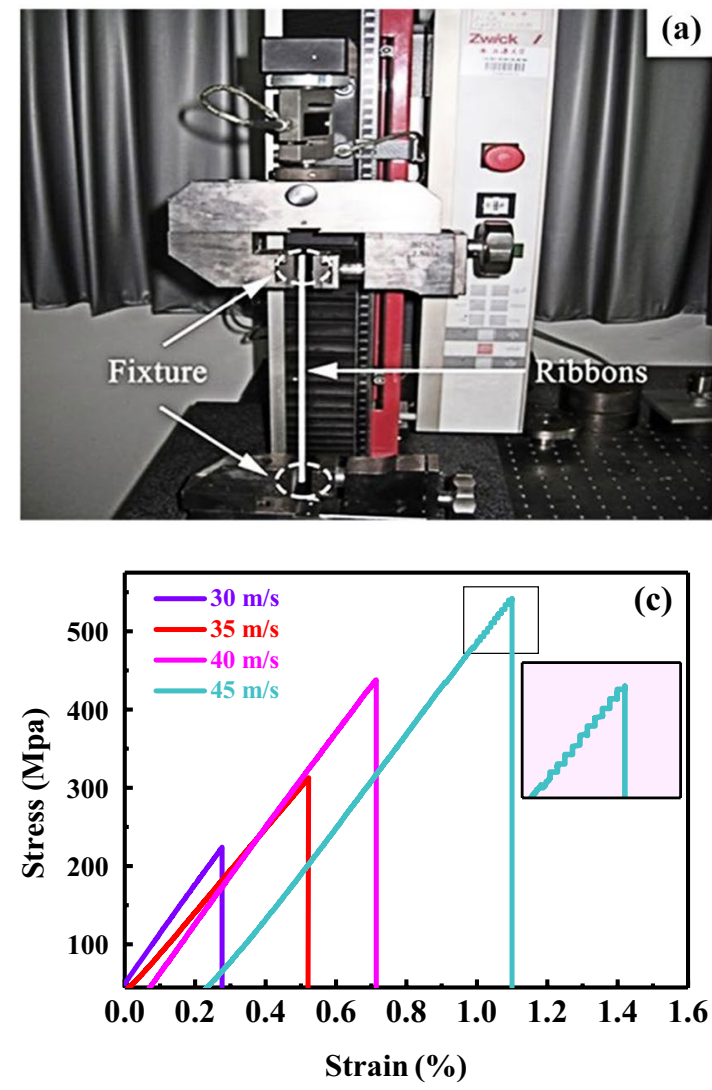

Figure 4 shows the physical morphology of the fractured surfaces of the samples at a spinning rate of $30 \mathrm{~m} \mathrm{~s}^{-1}$ (Fig. 4a, c) and $45 \mathrm{~m} \mathrm{~s}^{-1}$ (Fig. 4b, d). Figure $4 \mathrm{a}$ and c reveals that the fractured surface of ribbons exhibited a cleavage feature, which is the characteristic of brittle fracture. The reason is that with the increase of loading strain, the shear deformation occurs on the amorphous ribbons, resulting in highly localized strains. Finally, the brittle fracture occurs along a single shear zone. ${ }^{26}$

Figure $4 \mathrm{~b}$ and $\mathrm{d}$ shows that the fracture surface of ribbons exhibits a vein-like pattern which is attributed to a local change in viscosity along the shear zones. The main reason

Table II Mechanical properties of $\mathrm{Ti}_{47} \mathrm{Zr}_{31} \mathrm{Ni}_{14} \mathrm{Cr}_{8}$ alloy with different spinning rates

\begin{tabular}{llll}
\hline $\begin{array}{l}\text { Spinning rate } \\
(\mathrm{m} / \mathrm{s})\end{array}$ & $\begin{array}{l}\text { Tensile strength } \\
\sigma_{\mathrm{b}}(\mathrm{MPa})\end{array}$ & Elongation $\delta(\%)$ & $\begin{array}{l}\text { Elastic } \\
\text { modulus } E \\
(\mathrm{GPa})\end{array}$ \\
\hline 30 & $224 \pm 23$ & $0.28 \pm 0.03$ & 97.3 \\
35 & $318 \pm 25$ & $0.52 \pm 0.01$ & 66.1 \\
40 & $438 \pm 23$ & $0.71 \pm 0.01$ & 62.1 \\
45 & $542 \pm 22$ & $1.10 \pm 0.04$ & 44.6 \\
\hline
\end{tabular}
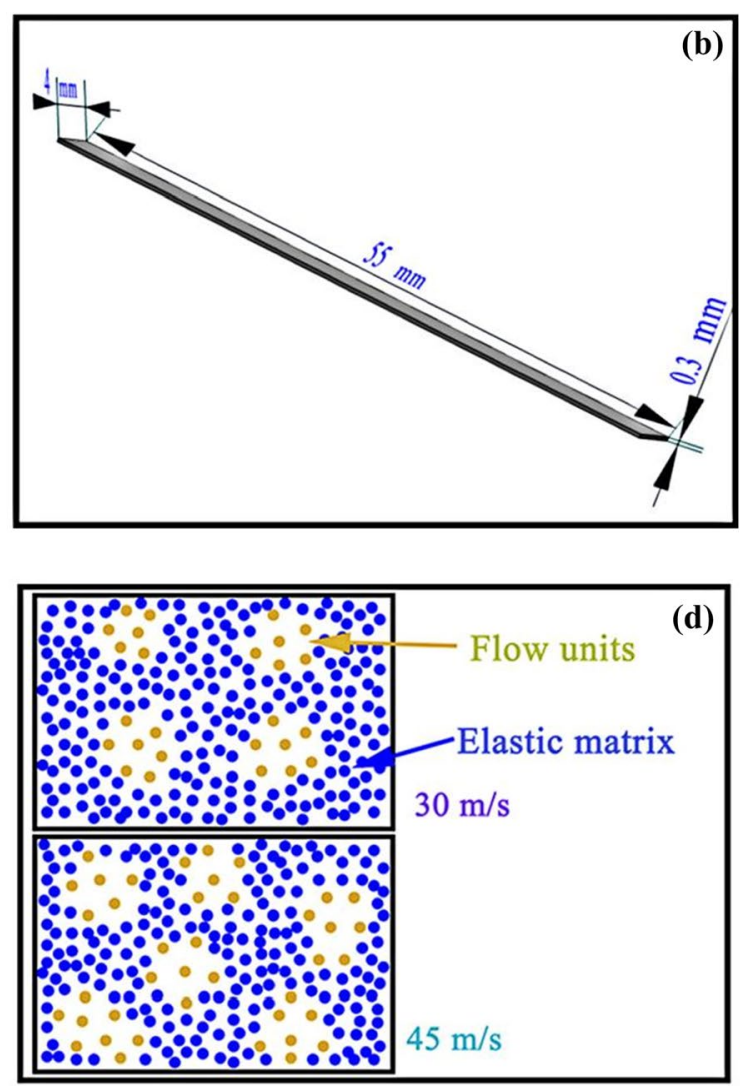

Fig. 3 (a) Zwick electronic universal testing machine; (b) ribbon size diagram; (c) stress-strain curve obtained from $\mathrm{Ti}_{47} \mathrm{Zr}_{31} \mathrm{Ni}_{14} \mathrm{Cr}_{8}$ amorphous ribbons; (d) a schematic of a flow units model with different spinning rates. 
Fig. 4 Fracture SEM images of the $\mathrm{Ti}_{47} \mathrm{Zr}_{31} \mathrm{Ni}_{14} \mathrm{Cr}_{8}$ melt-spun ribbons: (a) (c) melt-spun (30 $\left.\mathrm{m} \mathrm{s}^{-1}\right) \mathrm{Ti}_{47} \mathrm{Zr}_{31} \mathrm{Ni}_{14} \mathrm{Cr}_{8}$ alloy; (b) (d) melt-spun $\left(45 \mathrm{~m} \mathrm{~s}^{-1}\right)$ $\mathrm{Ti}_{47} \mathrm{Zr}_{31} \mathrm{Ni}_{14} \mathrm{Cr}_{8}$ alloy.
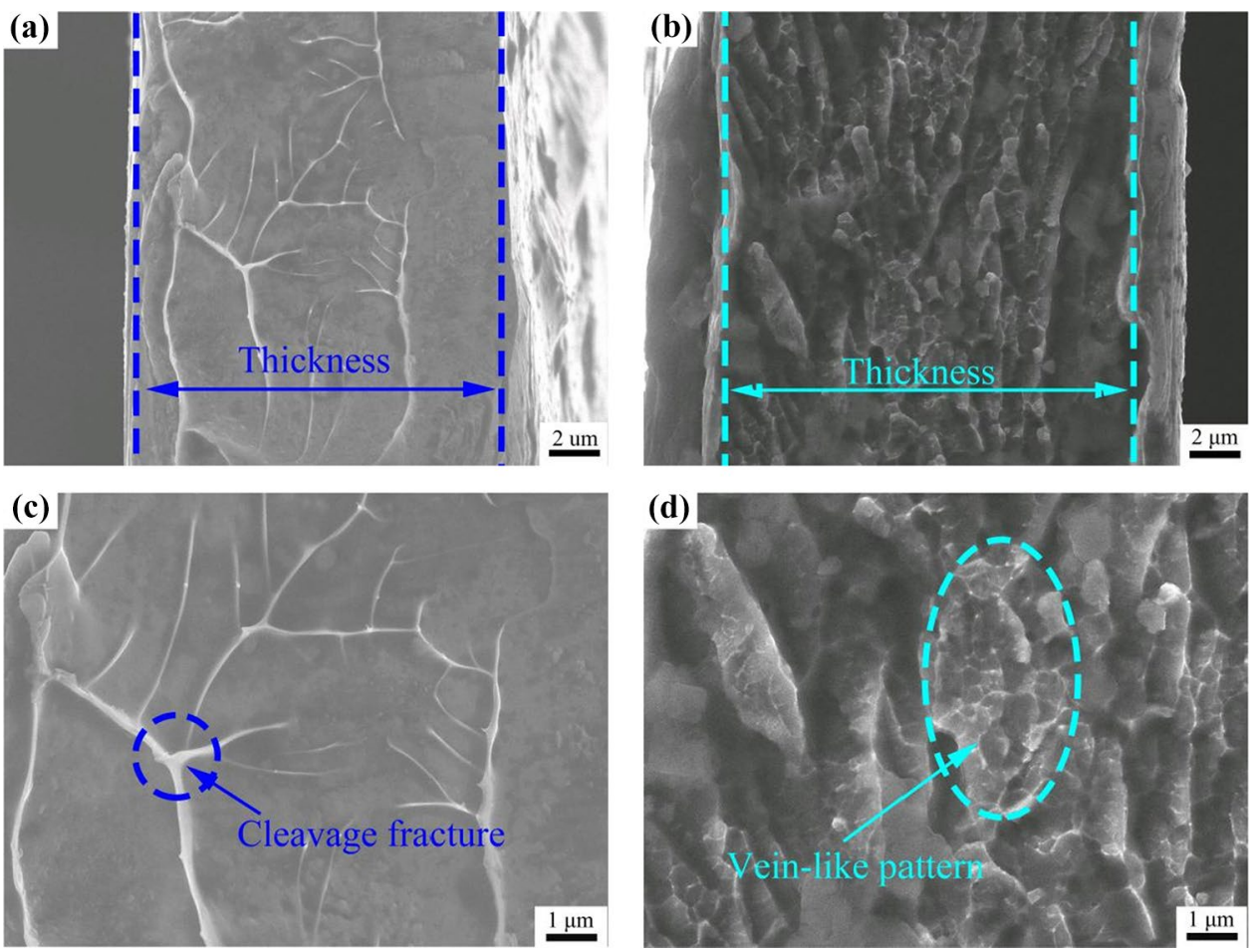

is that during the stretching process, the flow units first enter the stochastic activation stage. With the increase in loading strain, an increasing number of flow units were gradually activated and coordinated movement between adjacent flow units. Finally, these activated flow units began to penetrate each other and connect as a whole, and multiple shear zones were formed. ${ }^{27}$ The shear zone moves under stress, and when it encounters the elastic matrix, the motion is blocked. When the local stress of the elastic matrix exceeds a certain stress, the shear zone will continue to move beyond the elastic matrix. This local change in viscosity along the shear zones results in serrated flow and a macroscopic decrease in stress.

As the shear zone increased, a series of stress drop phenomena began to appear over time, resulting in a serrated flow phenomenon ${ }^{28-30}$ (Fig. 3c, inset). The results indicated that the flow units increase with the increase in the spinning rate in the amorphous ribbons. ${ }^{31}$ The flow unit model with different spinning rates is shown in Fig. 3d. It was also found that the mechanical properties and the plasticity of the amorphous ribbons were improved by increasing the spinning rate during the melt-spinning process.

Since amorphous alloys have good application prospects in hydrogen absorption, hydrogen absorption properties of amorphous alloys have been studied. The amorphous ribbons must be activated before hydrogen absorption. Activation means that the passivated surface that does not absorb gas becomes a fresh surface that can absorb gas again after being activated at high temperature in vacuum. ${ }^{32}$ The activation temperature must be below the glass transition

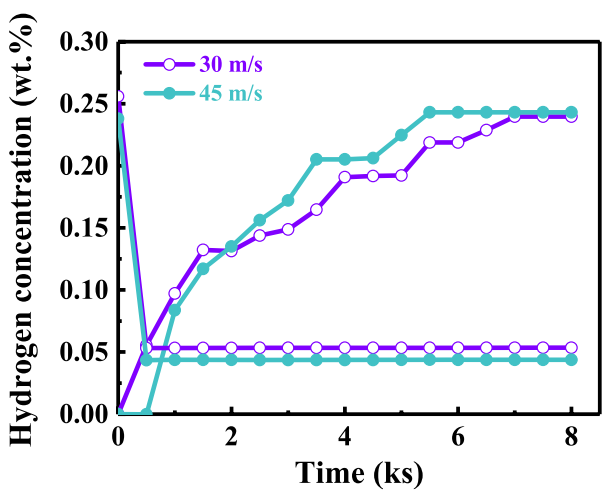

Fig. 5 Hydrogen absorption/desorption kinetics curves of $\mathrm{Ti}_{47} \mathrm{Zr}_{31} \mathrm{Ni}_{14} \mathrm{Cr}_{8}$ amorphous ribbons at the spinning rate of $45 \mathrm{~m} \mathrm{~s}^{-1}$.

temperature to ensure that the ribbons are still amorphous. Thus, according to the DSC curves, the activation temperature of the amorphous ribbons were determined to be $473 \mathrm{~K}$. Figure 6 shows that the phase structure before and after the amorphous ribbon activation remained consistent. Hydrogen absorption/desorption kinetic curves of amorphous ribbons after activation at $473 \mathrm{~K}$ under vacuum for $2 \mathrm{~h}$ are shown in Fig. 5.

Figure 5 shows that the hydrogen absorption capacity was consistent, but the hydrogenation kinetics and hydrogen desorption capacity were improved with the increase in the spinning rate. This means that improvement in hydrogen absorption kinetics and hydrogen desorption capacity may be associated with the increased spinning rate. This is 


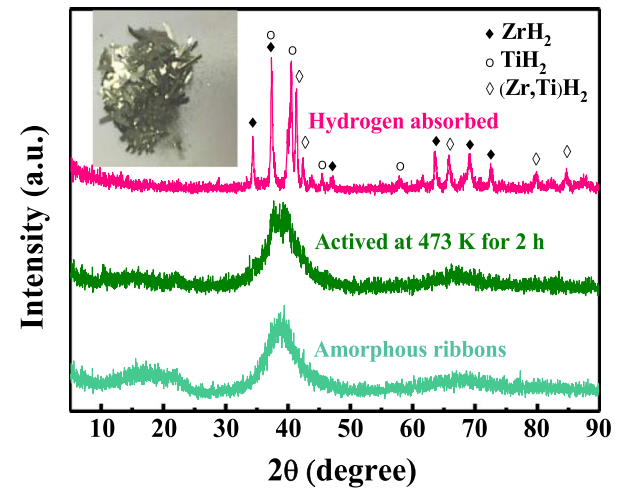

Fig. 6 Evolution of in situ XRD patterns for $\mathrm{Ti}_{47} \mathrm{Zr}_{31} \mathrm{Ni}_{14} \mathrm{Cr}_{8}$ meltspun alloy ribbons, activated and after hydrogen absorption when the spinning rate reached $45 \mathrm{~m} \mathrm{~s}^{-1}$; the inset shows the ribbons after hydrogen absorption.

because the loose clusters of atoms and flow units in amorphous alloys provide sites for hydrogen, and hydrogen enters the amorphous alloy first to occupy these locations. Due to the relatively loose arrangement of atoms in these locations, hydrogen more easily enters and exits at these locations. Therefore, with the increase in the spinning rates, the flow units increase, and the hydrogenation kinetics and the hydrogen desorption capacity are improved. ${ }^{33,34}$ After the sample absorbed a large amount of hydrogen, as shown in the phase composition exhibited in Fig. 6, the amorphous ribbons formed crystalline phases composed of $\mathrm{ZrH}_{2}, \mathrm{TiH}_{2}$, and $(\mathrm{ZrTi})_{2} \mathrm{Ni}_{7}$ phases. However, the sample after hydrogen absorption, as shown in the inset of Fig. 6, was pulverized and lost the mechanical properties. This indicated that the fragmentation of the sample was due to hydrogen entering the sample to promote phase decomposition.

\section{Conclusions}

In the present work, the mechanical properties, fracture mechanism, and hydrogen absorption/desorption properties of $\mathrm{Ti}_{47} \mathrm{Zr}_{31} \mathrm{Ni}_{14} \mathrm{Cr}_{8}$ amorphous ribbons with different spinning rates have been systematically investigated. When the spinning rate was greater than or equal to $30 \mathrm{~m} \mathrm{~s}^{-1}$, the alloys showed amorphous structure. With the spinning rate increased, the amorphous ribbons became more homogeneous. When the spinning rate was increased from $30 \mathrm{~m} \mathrm{~s}^{-1}$ to $45 \mathrm{~m} \mathrm{~s}^{-1}$, the tensile strength, elongation, and elastic modulus changed from $224 \mathrm{MPa}, 0.28 \%$, and $97.3 \mathrm{GPa}$ to 542 $\mathrm{MPa}, 1.1 \%$, and $44.6 \mathrm{GPa}$, respectively.

The fractured surface of ribbons exhibited a cleavage feature when the spinning rate was $30 \mathrm{~m} \mathrm{~s}^{-1}$. The fracture surface of the melt-spun ribbons at $45 \mathrm{~m} \mathrm{~s}^{-1}$ exhibited a vein-like pattern, which came from the interaction between the elastic matrix and the shear zones. These features provide better mechanical properties. With an increase in the flow units, the hydrogenation kinetics and hydrogen desorption capacity were improved. After the samples absorbed a large amount of hydrogen, the formation of crystalline phase of $\mathrm{ZrH}_{2}, \mathrm{TiH}_{2}$ and $(\mathrm{ZrTi})_{2} \mathrm{Ni}_{7}$ phases resulted in the loss of mechanical properties, which was mainly because hydrogen promotes the decomposition of phases and the formation of new phases.

Acknowledgments The authors thank the Analysis and Research Center of Shanghai University and Lanzhou Institute of Physics for their technical support. This work is supported by the Joint Research Fund in Astronomy (U1531120) under cooperative agreement between the National Natural Science Foundation of China (NSFC) and Chinese Academy of Sciences (CAS).

Conflict of interest We declare that we have no conflict of interest.

Open Access This article is licensed under a Creative Commons Attribution 4.0 International License, which permits use, sharing, adaptation, distribution and reproduction in any medium or format, as long as you give appropriate credit to the original author(s) and the source, provide a link to the Creative Commons licence, and indicate if changes were made. The images or other third party material in this article are included in the article's Creative Commons licence, unless indicated otherwise in a credit line to the material. If material is not included in the article's Creative Commons licence and your intended use is not permitted by statutory regulation or exceeds the permitted use, you will need to obtain permission directly from the copyright holder. To view a copy of this licence, visit http://creativecommons.org/licenses/by/4.0/.

\section{References}

1. S. Jan, Bulk metallic glasses. Phys. Today 66, 32 (2013).

2. C.A.C. Souza, D.V. Ribeiro, and C.S. Kiminami, Corrosion resistance of Fe-Cr-based amorphous alloys: an overview. J. Non Cryst. Solids 442, 56 (2016).

3. S. Jan, Condensed-matter physics: glasses made from pure metals. Nature 512, 142 (2014).

4. Q.M. Hu, and R. Yang, Mechanical properties of structural materials from first-principles. Curr. Opin. Solid State Mater. Sci. 10, 19 (2006).

5. P. Tao, Y. Yang, Z. Xie, and Y. He, Research on friction and wear behavior of a bulk metallic glass under different sliding velocity. Mater. Lett. 156, 177 (2015).

6. G. Tarjus, Materials science: metal turned to glass. Nature 448, 758 (2007).

7. M. Janik-Czachor, Anodic behavior of $\mathrm{Fe}_{40} \mathrm{Ni}_{40} \mathrm{~B}_{20}$ and $\mathrm{Fe}_{39} \mathrm{Ni}_{39} \mathrm{~B}_{10} \mathrm{Si}_{12}$ amorphous alloys. Mater. Corros. 34, 47 (1983).

8. E.V. Boltynjuk, D.V. Gunderov, E.V. Ubyivovk, M.A. Monclús, L.W. Yang, J.M. Molina-Aldareguia, A.I. Tyurin, A. Kilmametov, A.A. Churakova, and A.Y. Churyumov, Enhanced strain rate sensitivity of Zr-based bulk metallic glasses subjected to high pressure torsion. J. Alloys Compd. 747, 595 (2018).

9. Y.X. Geng, Y.M. Wang, Z.R. Wang, J.B. Qiang, H.B. Wang, C. Dong, and $\mathrm{O}$. Tegus, Formation and structure-property correlation of new bulk Fe-B-Si-Hf metallic glasses. Mater. Des. 106, 69 (2016).

10. J.M. Yang, Z.Y. Zhao, J. Mu, and Y.D. Wang, Effect of pre-plasticdeformation on mechanical properties of TiZr-based amorphous alloy composites. Mater. Sci. Eng. A Struct. 716, 23 (2018). 
11. M. Rajabi, A. Simchi, and P. Davami, Microstructure and mechanical properties of $\mathrm{Al}-20 \mathrm{Si}-5 \mathrm{Fe}-2 \mathrm{X}(\mathrm{X}=\mathrm{Cu}, \mathrm{Ni}, \mathrm{Cr})$ alloys produced by melt-spinning. Mater. Sci. Eng. A Struct. 492, 443 (2008).

12. T. Sahoo, B. Majumdar, V. Srinivas, M. Srinivas, T.K. Nath, and G. Agarwal, Improved magnetoimpedance and mechanical properties on nanocrystallization of amorphous $\mathrm{Fe}_{68.5} \mathrm{Si}_{18.5} \mathrm{Cu}_{1} \mathrm{Nb}_{3} \mathrm{~B}_{9}$ ribbons. J. Magn. Magn. Mater. 343, 13 (2013).

13. B. Jiang, J.X. Wang, L.F. Xu, C.Y. Qin, T.X. Liu, J.Y. Dai, and X.L. Hou, Tunable mechanical properties of Ti-Zr-Ni-Cr-V amorphous ribbons via different melt spinning speeds during rapid solidification process. Materials 11, 947 (2018).

14. B.Z. Liu, D.M. Liu, Y.M. Wua, L.Q. Li, and L.M. Wang, Hydrogen absorption in amorphous and quasicrystalline alloy powders. Int. J. Hydrog. Energy 32, 2429 (2007).

15. T. Liu, H.L. Shen, T.W. Zhang, W. Li, C.G. Qin, and T. Zhang, The influence of hydrogen absorption on the electrical resistivity and mechanical properties of $\mathrm{Zr}$-based amorphous alloy. J. NonCryst. Solids 365, 27 (2013).

16. Y.H. Zhang, C.H. Song, H.P. Ren, Z.G. Li, F. Hu, and D.L. Zhao, Enhanced hydrogen storage kinetics of nanocrystalline and amorphous $\mathrm{Mg} 2 \mathrm{~N}$-type alloy by substituting $\mathrm{Ni}$ with Co. Trans. Nonferr. Met. Soc. 21, 2002 (2011).

17. Y.H. Zhang, Z.C. Jia, Z.M. Yuan, Y. Qin, Z.H. Hou, and D.L. Zhao, Hydrogen storage thermodynamics and kinetics of $\mathrm{LaMg}_{11} \mathrm{Ni}+\mathrm{x}$ wt.\% $\mathrm{Ni}(\mathrm{x}=100,200)$ alloys synthesized by mechanical milling. Int. J. Mater. Res. 107, 348 (2016).

18. E.B. Kashkarov, N.N. Nikitenkov, A.N. Sutygina, A. Obrosov, A. Manakhov, J. Polcak, and S. Weiss, Hydrogen absorption by Tiimplanted Zr-1Nb alloy. Int. J. Hydrog. Energy 43, 2484 (2018).

19. X.L. Hou, Q.Q. Lu, X.C. Wang, B. Jiang, J.X. Wang, H. Xu, X.H. Tan, T.X. Liu, and J.Y. Dai, Atomic-scale structural evolution and crystallization mechanism of Ti-Zr-Ni-Cr amorphous ribbons during hydrogen absorption. J. Electron. Mater. 46, 3553 (2017).

20. J.O. Fadonougbo, J.Y. Suh, S. Han, C.H. Shim, G.H. Kim, M.H. Kim, E. Fleury, and Y.W. Cho, Hydrogen-induced decomposition of $\mathrm{Cu}-\mathrm{Zr}$ binary amorphous metallic alloys. J. Alloys Compd. 660, 456 (2016).

21. T. Liu, T.W. Zhang, W. Li, and G. Cheng, Hydrogen absorption and its influence on the thermal stability of $\mathrm{Zr}_{65} \mathrm{Al}_{10} \mathrm{Ni}_{10} \mathrm{Cu}_{15}$ amorphous alloy. Int. J. Hydrog. Energy 37, 9148 (2012).

22. T.B. Zhang, Y.L. Zhang, M. Zhang, R. Hu, H.C. Kou, J.S. Li, and X.Y. Xue, Hydrogen absorption behavior of Zr-based getter materials with Pd-Ag coating against gaseous impurities. Int. J. Hydrog. Energy 41, 14778 (2016).

23. N. Karatepe, and N. Yuca, Hydrogen adsorption on carbon nanotubes purified by different methods. Fuel Energy Abstr. 36, 11467 (2011).

24. H.J. Lin, L.Q. He, P. Zhang, Z.G. Zhang, S.P. Pan, and W. Li, Tailoring hydrogen storage properties of amorphous Mg65Cu25Y10 alloy via minor alloying addition of Ag. Intermetallics 97, 22 (2018).

25. S. Sarker, D. Chandra, M. Hirscher, M. Dolan, D. Isheim, J. Wermer, D. Viano, M. Baricco, T.J. Udovic, D. Grant, O. Palumbo, A. Paolone, and R. Cantelli, Developments in the Ni-Nb-Zr amorphous alloy membranes. Appl. Phys. A Mater. 122, 1 (2016).

26. F. Spaepen, A microscopic mechanism for steady state inhomogeneous flow in metallic glasses. Acta Metall. 25, 407 (2017).

27. L.Z. Zhao, R.J. Xue, Y.Z. Li, W.H. Wang, and H.Y. Bai, Revealing localized plastic flow in apparent elastic region before yielding in metallic glasses. J. Appl. Phys. 118, 637 (2015).

28. S.T. Liu, W. Jiao, B.A. Sun, and W.H. Wang, A quasi-phase perspective on flow units of glass transition and plastic flow in metallic glasses. J. Non-Cryst. Solids 376, 76 (2013).

29. Z. Wang, B.A. Sun, H.Y. Bai, and W.H. Wang, Evolution of hidden localized flow during glass-to-liquid transition in metallic glass. Nat. Commun. 5, 5823 (2013).

30. D.J. Lacks, and M.J. Osborne, Energy landscape picture of overaging and rejuvenation in a sheared glass. Phys. Rev. Lett. 93, 255 (2004).

31. L.Z. Zhao, R.J. Xue, Z.G. Zhu, Z. Lu, E. Axinte, W.H. Wang, and H.Y. Bai, Evaluation of flow units and free volumes in metallic glasses. J. Appl. Phys. 116, 259 (2014).

32. V. Chidambaram, X. Ling, and C. Bangtao, Titanium-based getter solution for wafer-level MEMS vacuum packaging. J. Electron. Mater. 42, 485 (2013).

33. D. Turnbull, and M.H. Cohen, Free-volume model of the amorphous phase: glass transition. J. Chem. Phys. 34, 120 (1961).

34. H.J. Lin, M. He, S.P. Pan, L. Gu, H.W. Li, H. Wang, L.Z. Ouyang, J.W. Liu, T.P. Ge, D.P. Wang, W.H. Wang, E. Akiba, and M. Zhu, Towards easily tunable hydrogen storage via a hydrogen-induced glass-to-glass transition in Mg-based metallic glasses. Acta Mater. 120, 68 (2016).

Publisher's Note Springer Nature remains neutral with regard to jurisdictional claims in published maps and institutional affiliations. 